\title{
Wacker doubles its dispersion capacity in China
}

W

acker Chemie AG has officially opened its new production plant for vinyl acetate-ethylene copolymer (VAE) dispersions at its Nanjing site in Jiangsu province in China. The additional 60,000 tonnes from the second reactor line doubles the local VAE dispersion capacity to give a total of 120,000 tonnes per year. This makes the plant complex one of the largest of its kind in China. At the same time, the Wacker Group is currently building a new plant at Nanjing to produce polyvinyl acetate (PVAc) solid resins with an annual capacity of 20,000 tonnes. It is scheduled to come on stream in late 2013. The investment in both projects amounts to around EUR 40 million.

The expansion of its dispersion plant is Wacker's response to the rising demand for high-quality VAE dispersions, especially in China and the emerging markets of south-east Asia. The goal of the

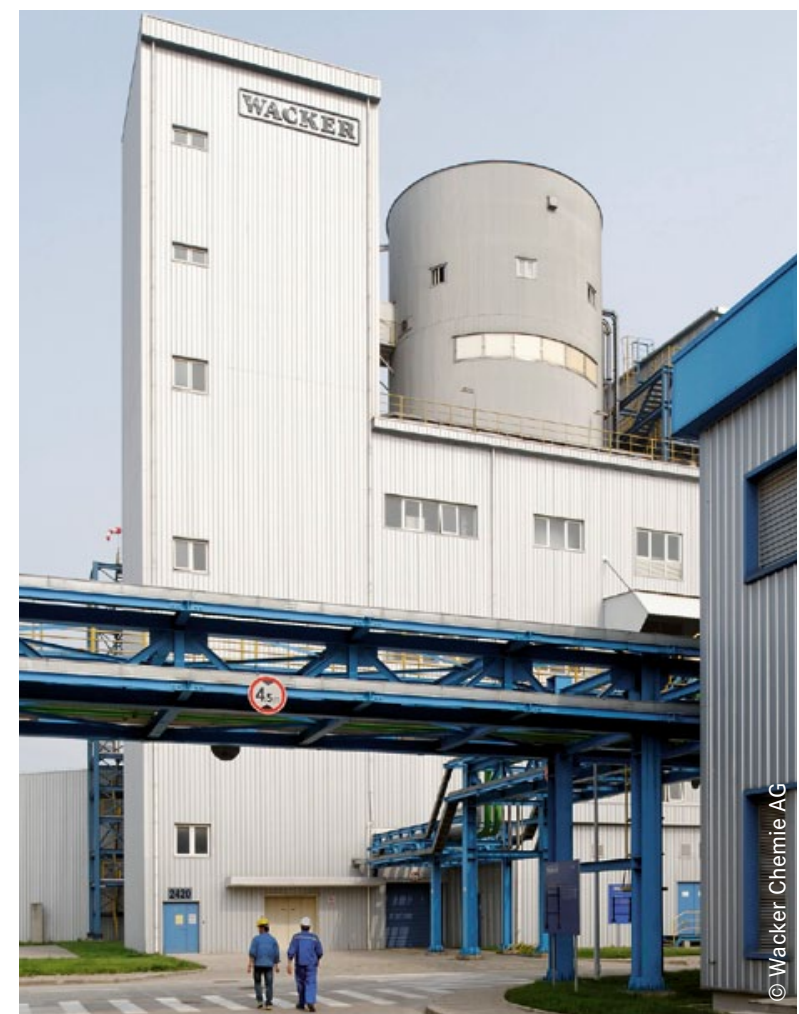

At its fully integrated site in Nanjing, Wacker is already manufacturing VAE dispersions and dispersible polymer powders used as binding agents in the construction, coatings and adhesives industries.

persions now and in future. As a result, Wacker will be able to offer its customers in the region consistently high product quality and long-term security of supply.

Wacker has already opened a new VAE production plant at its Ulsan site in South Korea in February. This can produce an additional 40,000 tonnes each year. As Dr. Rudolf Staudigl, CEO of Wacker Chemie AG, explained: "By expanding our production facilities in Korea and China, we are doubling our VAE capacity in the region and reinforcing our position as global leaders in this sector."

Located in the Nanjing Chemical Industrial Park, Wacker's fully integrated site already manufactures VAE dispersions and dispersible polymer powders for the construction, coatings and adhesives sectors. The second plant's ad-

investment is to ensure that the company has sufficient capacity to meet the strong demand for Vinnapas VAE disditional capacity is intended to support the strong growth in paint, paper, carpet and nonwoven applications.

\section{New German chemical sanctions ordinance}

The German Federal Environment Agency has introduced new sanctions for chemical users who breach their obligations under the terms of REACH.

Erom now on, anyone who breaches

- the REACH substance restrictions is committing a criminal offence and will be punished with a fine or a prison sentence of up to two years. If the life or health of other people or property belonging to third parties has deliberately been put at risk, imprisonment for a maximum of five years is possible. Anyone who acts illegally, for example by failing to disclose information to customers and users will be subject to a fine of up to EUR 50,000. These regulations form part of the new German chemical sanctions ordinance (known as ChemSanktionsV) which came into effect on 1 May 2013. It governs criminal offences and less serious illegal activities relating to various pieces of European legislation including $\mathrm{REACH}$, the regulation on chemicals.

Article 5 of the new ordinance covers criminal offences in relation to restric- tions and Article 6 lists the various illegal activities which are subject to the imposition of fines. These less serious illegal activities include the failure to report information to the European Chemicals Agency, the failure to meet a variety of obligations relating to the supply chain (for example, the safety data sheet and downstream users) and the failure to disclose to customers information about substances of very high concern in products. 